Gut, 1988, 29, 588-592

\title{
Perforating and non-perforating indications for repeated operations in Crohn's disease: evidence for two clinical forms
}

\author{
A J GREENSTEIN, P LACHMAN, D B SACHAR, J SPRINGHORN, \\ T HEIMANN, H D JANOWITZ, AND A H AUFSES Jr.
}

From the Departments of Surgery and Medicine (Division of Gastroenterology), Mount Sinai School of Medicine of the City University of New York and The Mount Sinai Hospital, New York, NY, USA

SUMmaRY The surgical indications in 770 patients with Crohn's disease undergoing intestinal resection at The Mount Sinai Hospital from 1960-83 have been reviewed. Surgical indications were divided into two principal categories: 375 cases with perforating indications and 395 cases nonperforating. Among 292 patients who underwent second operations for recurrent Crohn's disease, the indications for second operation were closely dependent on the indication for primary resection. Second operations were undertaken for perforating indications much more often among cases where the initial indication had been perforating, than among those whose initial indication had been nonperforating $(\mathbf{7 3 \%} v \mathbf{2 9 \%}, \mathbf{p}<\mathbf{0 . 0 0 0 0 1})$. This trend to similarities in the indications which bring patients to surgery was maintained within each anatomical category of Crohn's disease and even between second and third operations $(p<0 \cdot 001)$. Operations for perforating indications were followed by reoperation approximately twice as fast as operations for non-perforating indications, whether going from first to second operation (perforating $4.7 v$ non-perforating 8.8 years, $\mathbf{p}<0.001$ ), or from second to third (perforating $2.3 v$ non-perforating 5.2 years, $\mathbf{p}<0.005$ ). Crohn's disease thus seems to occur in two different clinical patterns, independent of anatomic distribution. These are a relatively aggressive perforating type and a more indolent non-perforating type, which tend to retain their identities between repeated operations and to influence the speed with which reoperation occurs.

Our recent studies of postoperative recurrence rates in Crohn's disease prompted us to suggest that there might be two different patterns of Crohn's disease, one inherently indolent, which tends to recur slowly, and the other inherently aggressive, which tends to recur quickly.' This concept was foreshadowed in 1971 by deDombal et al, who described early and late forms of recurrence. ${ }^{2}$ We wondered whether these two patterns of Crohn's disease could be characterised by differences in the indications which bring patients to surgery. To test this hypothesis, we have reviewed the indications for surgery in 770

Address for correspondence: Adrian J Greenstein, MD, Mount Sinai Medical Center, One Gustave L Levy Place, Department of Surgery - Box 1259, New York, NY 10029, USA.

Received for publication 2 November 1987.
Crohn's disease patients operated upon at The Mount Sinai Hospital between 1960 and 1983, in order to determine whether surgical indications tend to remain the same for repeated operations and whether they indeed influence the speed with which reoperation occurs.

\section{Methods}

PATIENTS

We have reviewed the records of 1415 patients with Crohn's disease admitted or readmitted to The Mount Sinai Hospital between 1960 and 1983. These patients comprised 554 with regional ileitis, 602 with ileocolitis, and 259 with Crohn's disease of the colon. Of these 1415 patients, 1072 had been operated 
upon: 444 with ileitis, 472 with ileocolitis, and 156 with strictly colonic disease. Patients were included in the study, however, only if they had undergone at least one intestinal resection at The Mount Sinai Hospital and only if the surgical indications were clearly defined in their records. Patients whose initial operations had been carried out before admission to The Mount Sinai Hospital were therefore-included only if subsequent surgery were done at this hospital and if the indication for primary operation elsewhere was clearly defined. Patients were also excluded if their course had been complicated by gastrointestinal malignancy. Among the 1072 operated patients, 302 were thus ultimately excluded for the following reasons: exclusively non-resectional surgery (bypass or incision and drainage), 121; no surgery at The Mount Sinai Hospital, 61; inadequate information concerning surgical indications, 88; and carcinoma, 32. These exclusions left a total of 770 patients in the study: 314 patients with ileitis, 345 with ileocolitis, and 111 with Crohn's disease of the colon $(\mathrm{M}: \mathrm{F}=370: 400)$.

Indications for the initial surgery were divided into two principal categories: perforating and nonperforating. Perforating indications included acute free perforation, subacute perforation with abscess formation, and chronic perforation with internal fistula formation. Non-perforating indications comprised intestinal obstruction, medical intractability, haemorrhage, and toxic dilatation without perforation. If any perforating indication was present, the case was classified as perforating, regardless of the concomitant presence of additional non-perforating indications. Indications for surgery were determined from a review of the clinical findings, from preoperative diagnostic studies such as small bowel series and barium enema, from findings at laparotomy, and from postoperative pathological evidence. Indications for successive operations in the same patient were classified separately and independently from each other. Differences in the distribution of indications between successive operations were analysed by the $\chi^{2}$ test using a $2 \times 2$ contingency table. Comparisons of interoperative intervals were carried out using the non-paired $t$ test.

\section{Results}

Among the 770 patients included in this study, 375 $(49 \%)$ had perforating indications for initial resection, and $395(51 \%)$ non-perforating indications (Table 1). Of these 770 surgical patients, 292 under-

Table 1 Perforating and non-perforating indications for primary resection in 770 cases of Crohn's disease

\begin{tabular}{lclc}
\hline Perforating & indications & \multicolumn{1}{c}{ Non-perforating indications } \\
\hline Fistula & 240 & Obstruction & 239 \\
Abscess & 91 & Intractability & 132 \\
Acute free & 44 & Haemorrhage & 15 \\
\multicolumn{1}{c}{ perforation } & & Toxic dilatation & 9 \\
& & (without perforation) & \\
Total & $375(49 \%)$ & Total & $395(51 \%)$ \\
\hline
\end{tabular}

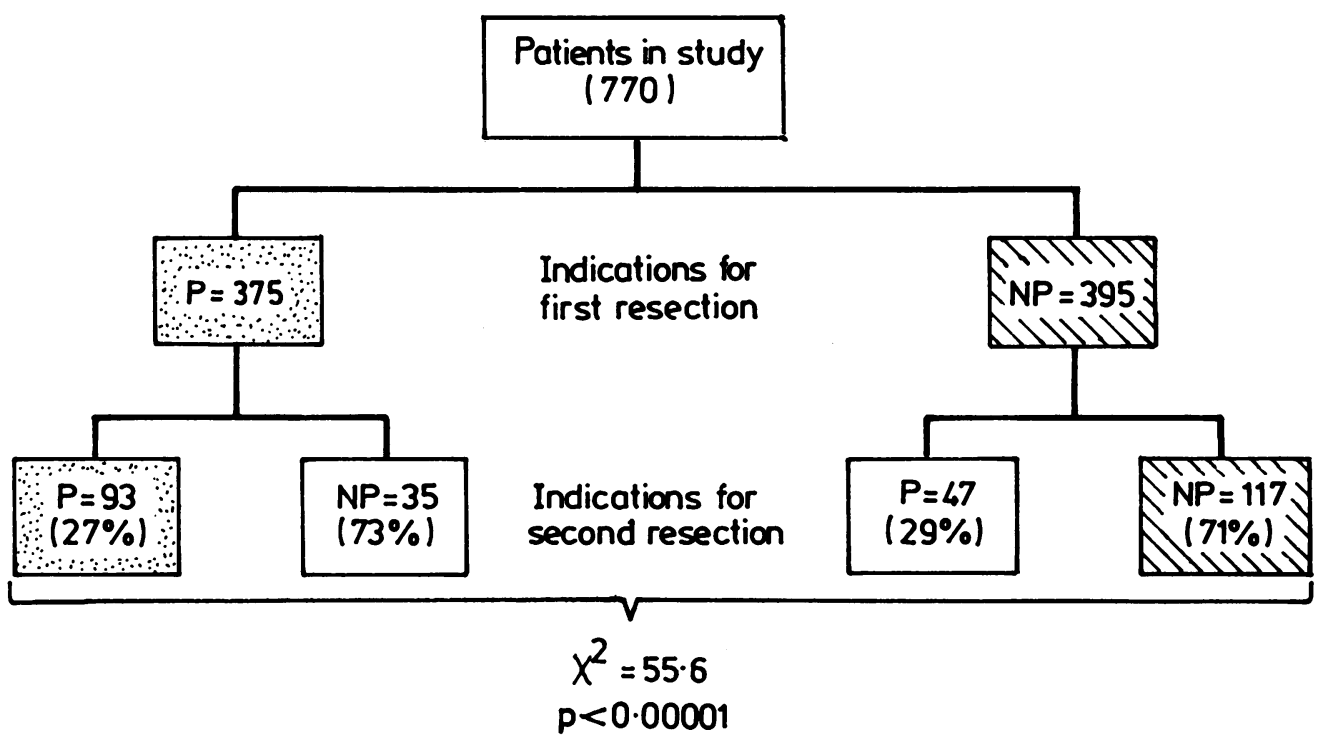

Fig. 1 Distribution of perforating and non-perforating indications for surgery between first and second resection. 


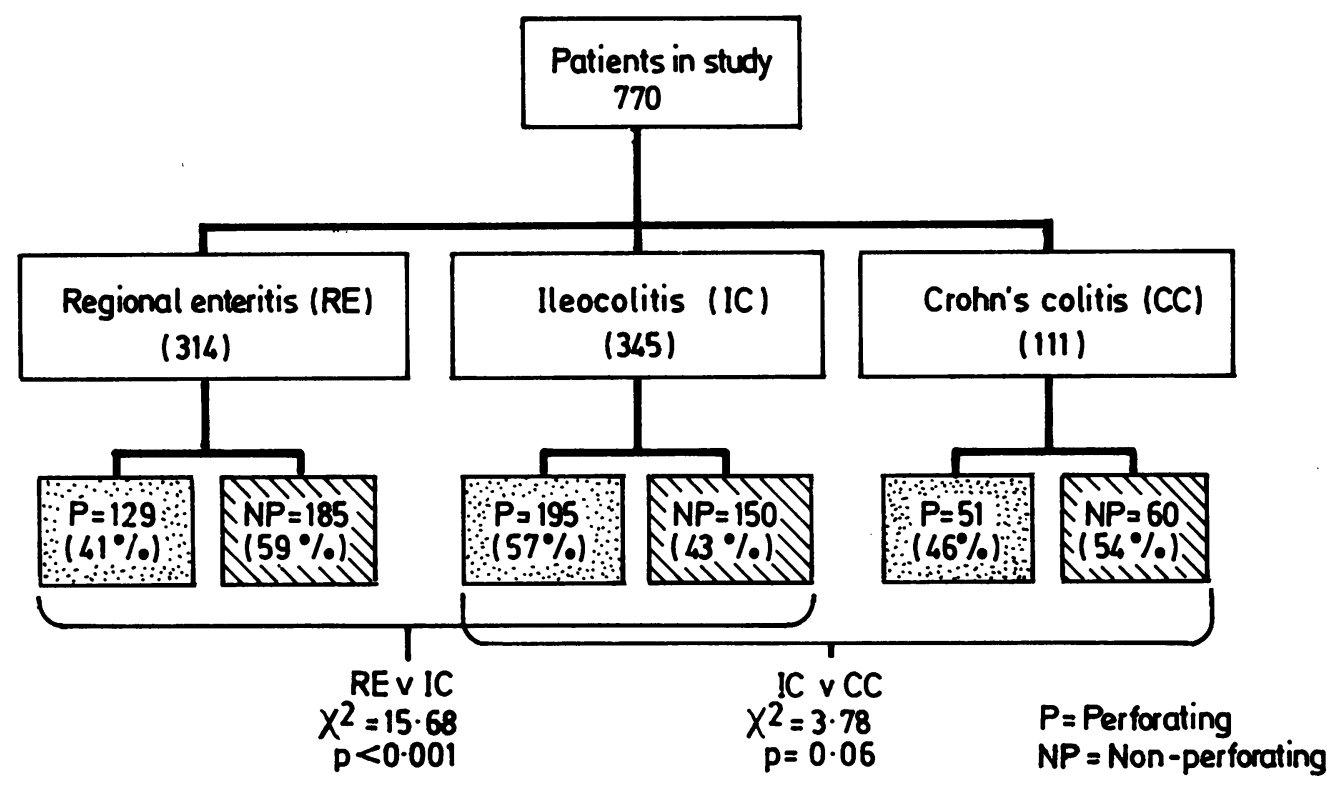

Fig. 2 Proportions of perforating and non-perforating indications for surgery among the three anatomic categories of Crohn's disease.

went a second operation, 88 had a third operation, and 16 went on to a fourth.

Analysis of the surgical indications in the overall series showed striking differences in the indications for the second operation, depending upon the indication for the primary resection (Fig. 1). Of the 128 reoperated patients who had presented with a perforating indication at the first operation, $93(73 \%)$ again had a perforating indication for the second operation. By contrast, only 47 of the 164 reoperated patients $(29 \%)$ whose initial surgical indication had been non-perforating developed a perforating indication for second operation. This difference is highly statistically significant $\left(\chi^{2}=55 \cdot 6, p<0 \cdot 00001\right)$.

There were no significant differences between those patients with perforating and non-perforating indications in their mean ages either at onset of Crohn's disease (24.1 and $25 \cdot 3$ years respectively) or at time of first resection ( 31.0 years for both groups). The distribution of perforating indications for primary operation did vary somewhat among the different anatomic categories of Crohn's disease (Fig. 2), with a significantly higher proportion of nonperforating indications in ileitis $(59 \%)$ than in ileocolitis $(43 \%)$. Nonetheless, the heavy dependence of indication for second operation upon the indication for primary operation was still maintained within each of these three anatomical categories. In ileitis - for example (Table 2), second operations were carried out for perforating indications more frequently among cases where initial indication had been perforating than among those whose initial indication had been non-perforating $(64 \% v 26 \%$, respectively; $p<0 \cdot 005)$. Similar differences were also seen within the groups with ileocolitis (Table 3) and Crohn's disease of the colon (Table 4), although the

Table 2 Perforating and non-perforating indications for first and second resections in 314 patients with ileitis

\begin{tabular}{|c|c|c|c|}
\hline & & \multicolumn{2}{|c|}{ Indication for first resection } \\
\hline & & $\begin{array}{l}\text { Perforating } \\
(n=129)\end{array}$ & $\begin{array}{l}\text { Non-perforating } \\
(n=185)\end{array}$ \\
\hline $\begin{array}{l}\text { Indications for } \\
\text { second resection }\end{array}$ & $\begin{array}{l}\text { Perforating } \\
\text { Non-perforating }\end{array}$ & $\begin{array}{r}16(64 \%) \\
9(36 \%)\end{array}$ & $\begin{array}{l}17(26 \%) \\
49(74 \%)\end{array}$ \\
\hline Totals & & 25 & 66 \\
\hline
\end{tabular}

$\chi^{2}=11 \cdot 47 ; p<0.005$.

Table 3 Perforating and non-perforating indications for first and second resections in 345 patients with ileocolitis

\begin{tabular}{|c|c|c|c|}
\hline & & \multicolumn{2}{|c|}{ Indication for first resection } \\
\hline & & $\begin{array}{l}\text { Perforating } \\
(n=195)\end{array}$ & $\begin{array}{l}\text { Non-perforating } \\
(n=150)\end{array}$ \\
\hline $\begin{array}{l}\text { Indications for } \\
\text { second resection } \\
\text { Totals }\end{array}$ & $\begin{array}{l}\text { Perforating } \\
\text { Non-perforating }\end{array}$ & $\begin{array}{l}64(77 \%) \\
19(23 \%) \\
83\end{array}$ & $\begin{array}{l}24(29 \%) \\
60(71 \%) \\
84\end{array}$ \\
\hline
\end{tabular}

$\chi^{2}=39 \cdot 46 ; p<0 \cdot 00001$. 


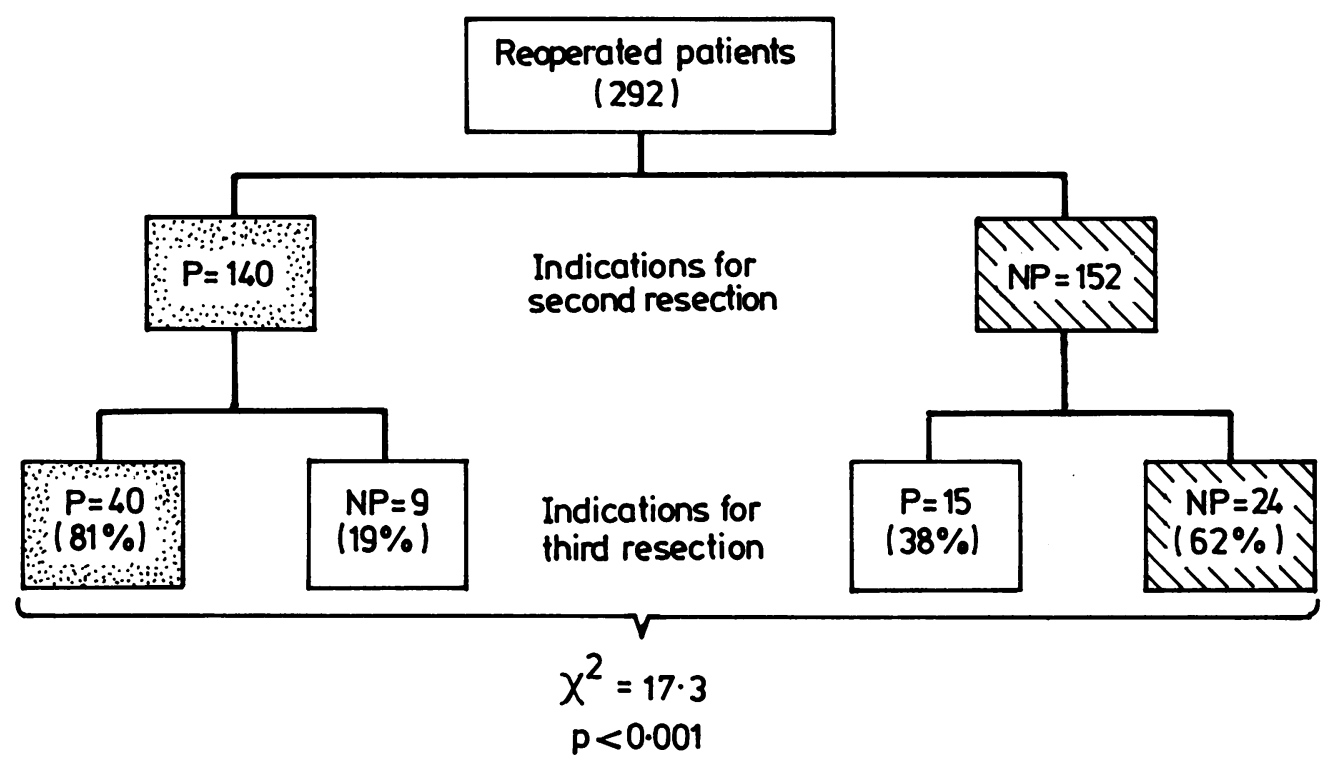

Fig. 3 Distribution of perforating and non-perforating indications between second and third resections.

numbers in the latter category are too small to achieve statistical significance.

There were 88 patients who had three or more operations. Among them, the same pattern of differences was again found in indications for third operation, depending upon the indication for the second resection (Fig. 3). Third operations were performed for perforating indications much more often among cases where second resection had been for perforation than among those whose prior indication had been non-perforating $(81 \% \vee 38 \%$, respectively; $\mathrm{p}<0 \cdot 001)$.

Operations for perforating indications were followed by reoperation approximately twice as fast as operations for non-perforating indications. Mean interval between first and second operations was $8 \cdot 8$ years when first operations were for non-perforating indications, but only 4.7 years when they were for perforating indications $(t=4 \cdot 01, d f=271, p<0 \cdot 001)$.

Table 4 Perforating and non-perforating indications for first and second resections in 111 patients with Crohn's colitis

\begin{tabular}{|c|c|c|c|}
\hline & & \multicolumn{2}{|c|}{ Indication for first resection } \\
\hline & & $\begin{array}{l}\text { Perforating } \\
(n=51)\end{array}$ & $\begin{array}{l}\text { Non-perforating } \\
(n=60)\end{array}$ \\
\hline $\begin{array}{l}\text { Indications for } \\
\text { second resection } \\
\text { Totals }\end{array}$ & $\begin{array}{l}\text { Perforating } \\
\text { Non-perforating }\end{array}$ & $\begin{array}{c}13(65 \%) \\
7(35 \%) \\
20\end{array}$ & $\begin{array}{l}6(43 \%) \\
8(57 \%) \\
14\end{array}$ \\
\hline
\end{tabular}

$\chi^{2}=1 \cdot 6 ; p>0 \cdot 95$
Likewise, mean interval between second and third operations was $5 \cdot 2$ years when second operations were for non-perforating indications, but only $2 \cdot 3$ years when second operations were for perforating indications $(t=2 \cdot 8, d f=79, p<0 \cdot 005)$.

\section{Discussion}

Our findings agree with those of Farmer and coworkers that the particular indications for surgery in Crohn's disease vary to some extent depending upon the anatomical distribution of the disease. ${ }^{3}$ The most common indications for operation in ileitis are non-perforating, especially intestinal obstruction, whereas ileocolitis patients come to surgery more often for perforating complications, especially fistulae. Despite these anatomically based differences, however, the more striking finding of our study is that indications for surgery tend to remain the same from initial to subsequent operations, regardless of anatomical category of disease.

Moreover, time intervals between successive operations also appear to vary with the type of surgical indication; operations for perforating indications were followed by reoperation approximately twice as fast as operations for non-perforating indications. This observation is very similar to that recently reported for fistula and abscess by Whelan et al. ${ }^{4}$ Our finding of a shorter interval between second and third operations than between first and second procedures is also in accord with previous observations. ${ }^{5-7}$

These differences in time intervals between opera- 
tions account for the apparent paradox of a slightly higher overall frequency of reoperation after initial surgery for non-perforating indications $(164 / 395=$ $42 \%$ ) than after initial surgery for perforating indications $(128 / 395=34 \%)$. Although the crude frequency was indeed marginally higher in the non-perforating group, it took twice as long to reach this number, so that the rate of reoperation was actually lower. New studies of this issue utilising life table methods are currently underway.

Meanwhile, the results of the present study tend to support our concept of inherently 'aggressive' and 'indolent' forms of Crohn's disease' ${ }^{1}$ as suggested earlier by the Leeds group. ${ }^{2}$ A determining factor in these patterns may be the amount of fibrosis. We may speculate that those cases with considerable fibrosis will be more likely to be obstructed intermittently and to have intractable symptoms leading gradually to non-perforating indications for surgery. On the other hand, those cases with less fibrosis, in which deep ulceration with fissure or fistula formation is the dominant pathological feature, may lead more quickly to surgery for perforating indications.

Although multivariate regression analysis in our previous studies have shown little influence of other clinical and pathological features, ' the present study has not specifically analysed the effects of some of these potentially confounding variables, such as demographic characteristics, laboratory features, medical therapies, or surgical pathology. Nonetheless, our concept of two different clinical forms of Crohn's disease, one more indolently cicatrising and one more aggressively perforating, may prove to be a useful starting point for future studies of natural history, treatment, and prognosis.

The authors wish to thank Jean DiCarlo for her excellent assistance in the preparation of this manuscript and Devaprasad Reuben RRA, for obtaining the medical records from the computer files of the hospital and assisting in analysing and collating the data.

\section{References}

1 Sachar DB, Wolfson DM, Greenstein AJ, Goldberg J, Janowitz HD. Risk factors for postoperative recurrence in Crohn's disease. Gastroenterology 1983; 85: 917-21.

2 DeDombal FT, Burton I, Goligher JC. Recurrence of Crohn's disease after primary excisional surgery. Gut 1971; 12: 519-27.

3 Farmer RG, Hawk WA, Turnbull RB Jr. Indications for surgery in Crohn's disease. Gastroenterology 1976; 71: 245-50.

4 Whelan G, Farmer RG, Fazio VW, Goormastic M. Recurrence after surgery in Crohn's disease. Gastroenterology 1985; 88: 1826-33.

5 Greenstein AJ, Sachar DB, Pasternack BS, Janowitz HD. Reoperation and recurrence in Crohn's colitis and ileocolitis: crude and cumulative rates. $N$ Engl J Med 1975; 293: 685-90.

6 Lennard-Jones JE, Stalder GA. Prognosis after resection of chronic ileitis. Gut 1967; 8: 332-6.

7 Lock MR, Fazio VW, Farmer RG, Jagelman DG, Lavery IC, Weakley FL. Proximal recurrence and the fate of the rectum following excisional surgery for Crohn's disease of the large bowel. Ann Surg 1981; 194: 754-60. 